University of Wollongong

Research Online

Faculty of Engineering and Information

Faculty of Engineering and Information

Sciences - Papers: Part A

Sciences

$1-1-2015$

The impact of electronic medication administration records in a residential aged care home

Siyu Qian

University of Wollongong, sq992@uowmail.edu.au

Ping Yu

University of Wollongong, ping@uow.edu.au

David M. Hailey

University of Wollongong, dhailey@uow.edu.au

Follow this and additional works at: https://ro.uow.edu.au/eispapers

Part of the Engineering Commons, and the Science and Technology Studies Commons

Research Online is the open access institutional repository for the University of Wollongong. For further information contact the UOW Library: research-pubs@uow.edu.au 


\title{
The impact of electronic medication administration records in a residential aged care home
}

\author{
Abstract \\ This study aimed to compare between electronic medication administration records and paper-based \\ records in the nursing time spent on various activities in a medication round and the \\ medicationadministration processes followed by nurses in an Australian residential aged care home. It \\ also aimedto identify the benefits and unintended adverse consequences of using the electronic \\ medication admin-istration records. Methods: Time-motion observation, taking of field notes, informal \\ conversation and document reviewwere used to collect data in two units of a residential aged care home. \\ Each unit had one nurse admin-ister medication. Seven nurses were observed over 12 morning shifts. Unit \\ 1 used electronic medicationadministration records and Unit 2 used paper-based records. Results: No \\ significant difference between the two units was found in the nursing time spent on variousactivities in a \\ medication round, including documentation, verbal communication, medication adminis-tration, infection \\ control and transit.Comparison of the medication administration processes between the electronic and \\ paper-basedmedication administration records identified a procedural problem which violated the \\ organization'sdocumentation requirement. This problem was documenting before providing medication to \\ a residentwhen using the paper-based records. It was not observed with the electronic medication \\ administrationrecords.Benefits of introducing the electronic medication administration records included \\ improving nurses'compliance with documentation requirements, freedom from the error of signing twice, \\ reducing thepossibility of forgetting to medicate a resident, facilitating nurses to record the time of \\ medicationadministration to a resident and increasing documentation space. Unintended adverse \\ consequencesof introducing the electronic medication administration records included inadequate \\ information aboutresidents, late addition of a new resident's medication profile in the records and nurses' \\ forgetting tomedicate a resident due to power outage of the portable device.Conclusions: The electronic \\ medication administration records may not change nursing time spent onvarious activities in a \\ medication round or substantially alter the medication administration processes,but can generate both \\ benefits and unintended adverse consequences. Future research may investigatewhether and how the \\ adverse consequences can be prevented. \\ Disciplines \\ Engineering | Science and Technology Studies
}

\section{Publication Details}

Qian, S., Yu, P. \& Hailey, D. M. (2015). The impact of electronic medication administration records in a residential aged care home. International Journal of Medical Informatics, 84 (11), 966-973.

This journal article is available at Research Online: https://ro.uow.edu.au/eispapers/5042 


\section{Title page}

Title: The impact of electronic medication administration records in a residential aged care home

Journal: International Journal of Medical Informatics

\section{Authors:}

First author: Siyu QIAN, PhD

Second author: Ping YU, Associate Professor, PhD

Third author: David M. HAILEY, Professor, PhD

\section{Affiliation:}

School of Computing and Information Technology, University of Wollongong, New South Wales 2522, Australia.

\section{Corresponding Author:}

Associate Professor Ping Yu

School of Computing and Information Technology

University of Wollongong

New South Wales (NSW) 2522

Australia

Telephone: +61 242215412

Fax: +61 242214170

Email:ping@uow.edu.au 


\title{
The impact of electronic medication administration records in a residential aged care home
}

\begin{abstract}
Purposes: This study aimed to compare between electronic medication administration records and paper-based records in the nursing time spent on various activities in a medication round and the medication administration processes followed by nurses in an Australian residential aged care home. It also aimed to identify the benefits and unintended adverse consequences of using the electronic medication administration records.
\end{abstract}

Methods: Time-motion observation, taking of field notes, informal conversation and document review were used to collect data in two units of a residential aged care home. Each unit had one nurse administer medication. Seven nurses were observed over 12 morning shifts. Unit 1 used electronic medication administration records and Unit 2 used paper-based records.

Results: No significant difference between the two units was found in the nursing time spent on various activities in a medication round, including documentation, verbal communication, medication administration, infection control and transit.

Comparison of the medication administration processes between the electronic and paperbased medication administration records identified a procedural problem which violated the organization's documentation requirement. This problem was documenting before providing medication to a resident when using the paper-based records. It was not observed with the electronic medication administration records.

Benefits of introducing the electronic medication administration records included improving nurses' compliance with documentation requirements, freedom from the error of signing 
twice, reducing the possibility of forgetting to medicate a resident, facilitating nurses to record the time of medication administration to a resident and increasing documentation space. Unintended adverse consequences of introducing the electronic medication administration records included inadequate information about residents, late addition of a new resident's medication profile in the records and nurses' forgetting to medicate a resident due to power outage of the portable device.

Conclusions: The electronic medication administration records may not change nursing time spent on various activities in a medication round or substantially alter the medication administration processes, but can generate both benefits and unintended adverse consequences. Future research may investigate whether and how the adverse consequences can be prevented.

Keywords: Benefit; electronic medication administration records; nursing home; process; time; unintended adverse consequence 


\section{Introduction}

Managing medication for the frail elderly is challenging [1]. Research has found that residents living in residential aged care homes (RACHs) were prescribed significantly more medications than those living independently [2]. International studies found that residents in RACHs were prescribed an average of seven to nine medications [3-5]. As various healthcare workers such as doctors, pharmacists and nursing staff collaboratively work in the medication management process [6], and each needs to make specific decisions and actions, this process can be error-prone [7].

It is believed that electronic medication administration records (eMAR) can reduce medication errors and improve efficiency $[8,9]$. This expectation has driven some RACHs to implement eMAR. However, there is a paucity of empirical evidence to suggest whether and how eMAR can meet the stated expectations.

Vogelsmeier et al. [10] used multiple methods including observation, process mapping, key informant interviews and field notes to explore workarounds to eMAR in five RACHs. The eMAR were used on a portable device with a touchscreen. The study found that there were some workflow blocks intentionally designed in the eMAR to improve resident safety, for example documenting after preparing medication and documenting again after providing medication. However, staff overrode these blocks because they felt that they were cumbersome or time consuming. The study also found some unintentional adverse blocks (e.g. limited fax capacity). The staff had to work around these blocks in order to complete tasks.

The study conducted by Vogelsmeier et al. was part of a larger study summarized by ScottCawiezell et al. [1]. Scott-Cawiezell et al. reported that implementation of the eMAR was guided by the medication safety team of each RACH. Use of the eMAR created some benefits such as shortened medication order entry process, improved clarity of the medication 
administration records and provision of real-time data to the healthcare provider. However the use of the eMAR could not solve the workaround issue in isolation. An effective mechanism needed to be developed by the medication safety teams, in consideration of the functionality of the eMAR to maximize its benefits and minimize or eliminate the adverse consequences [1].

The findings from these studies suggest that the actual way that eMAR are used by the staff on the floor may limit the effectiveness of eMAR and prevent realization of the expected benefits. More evidence about how eMAR can be used effectively to improve resident safety and documentation efficiency is needed. This will direct management in designing relevant, targeted intervention mechanisms to improve the effectiveness of eMAR.

The study reported here aimed to investigate the impact of eMAR in an Australian RACH. It addressed the following three questions: 1) Compared with paper-based records, do eMAR impact nursing time spent on various activities in a medication round? 2) What are the processes that a nurse might follow in use of eMAR or paper-based records to medicate a resident? 3) What are the benefits and unintended adverse consequences of introducing eMAR?

In Australia, RACHs provide aged care services to older people who can no longer live by themselves at home. Residential aged care services are provided at two levels: low care and high care. Low-care homes, also known as hostels, provide accommodation, laundry, meals, cleaning services and personal care (e.g. showering, dressing and toileting). High-care homes, also known as nursing homes, provide 24-hour nursing care (e.g. medication administration) in addition to low-care services. Residential aged care homes which allow low-care residents to remain in the same place instead of transferring to a high-care home as their dependency 
increases are called aging-in-place RACHs. This study was conducted in an aging-in-place RACH.

\section{Methods}

This study used multiple methods, including time-motion based observation, informal conversation with medication staff, field notes and document review, to collect both quantitative and qualitative data in morning shifts in the aging-in-place RACH.

\subsection{Settings and staffing}

This RACH had five care units. This study was conducted in two of these units. Resident case mix in these two care units was that $97 \%$ of the residents required a high level of care. Their average age was 83 years old and the average length of stay was one year.

Unit 1 had 38 beds and Unit 2 had 40 beds. The two units shared one medication room in which medications were stored and medication trolleys were placed. Each unit had an office where the staff could do documentation on desktop computers. Unit 1 used eMAR while Unit 2 used paper-based medication administration records during a medication round. In each unit, one medication staff member administered medication to residents in a morning shift.

Types of medication staff members included registered nurses, endorsed enrolled nurses and personal carers with Certificate IV Level II in medication management awarded by Australian Technical and Further Education colleges.

The staffing strategy was that at Unit 1 , only registered nurses and endorsed enrolled nurses could administer medication, because they had the qualification to medicate residents who used percutaneous endoscopic gastrostomy feeding tubes. During the study period, the number of residents used percutaneous endoscopic gastrostomy feeding tubes ranged from one to three. At Unit 2, all three types of medication staff could administer medication. 


\subsection{Participants}

Medication staff members who often worked in morning shifts were invited to participate in the study. Seven medication staff members gave consent. They worked regularly in the two units to cover at least $80 \%$ of the morning shifts, therefore their work activities were representative of those in the two units. They comprised one registered nurse, four endorsed enrolled nurses and two personal carers with Certificate IV level II in medication management.

Table 1 shows the demographics of these participants and the number of times a participant was observed. Their average years of work experience in medication administration were six years, with a minimum of five months to a maximum of 13 years. One participant was male.

At Unit 1, only endorsed enrolled nurses were observed, because the registered nurse was not scheduled to work in this unit at the time of observation. At Unit 2, all three types of nurses were observed. Participants who worked more shifts were observed more times. The observer made the best effort to reflect the roster pattern of the participants, given the constraints of change in staff roster, availability of the observer and study timeframe.

Table 1. Demographics of the participants and the number of times a participant was observed.

\begin{tabular}{|c|c|c|c|c|}
\hline \multirow{2}{*}{ Medication staff members } & \multirow{2}{*}{ Gender } & \multirow{2}{*}{$\begin{array}{l}\text { Work experience in } \\
\text { medication } \\
\text { administration }\end{array}$} & \multicolumn{2}{|c|}{ Number of times observed } \\
\hline & & & Unit 1 & Unit 2 \\
\hline Registered nurse & female & 5 months & - & 1 \\
\hline Endorsed enrolled nurse 1 & female & 7 years & 2 & 1 \\
\hline Endorsed enrolled nurse 2 & female & 8 years & 1 & - \\
\hline Endorsed enrolled nurse 3 & female & 13 years & 2 & - \\
\hline Endorsed enrolled nurse 4 & male & 8 years & 1 & 1 \\
\hline $\begin{array}{l}\text { Personal carer } 1 \text { with Certificate } \\
\text { IV level II in medication } \\
\text { management }\end{array}$ & female & 7 years & - & 2 \\
\hline $\begin{array}{l}\text { Personal carer } 2 \text { with Certificate } \\
\text { IV level II in medication } \\
\text { management }\end{array}$ & female & 6 months & - & 1 \\
\hline
\end{tabular}




\subsection{The functions and workflows designed in the eMAR}

The eMAR at the RACH had been in use for 18 months. They were accessible on five desktop computers and at the point-of-care on two touchscreen portable devices. Each nurse was assigned a unique user name and password to use the eMAR.

The workflow designed in the eMAR was that after the login page, several options of the start time of a medication round were displayed. This was followed by a resident list screen which showed who needed medication during the selected medication round time. Each resident record on the list noted medication 'status', the person's 'room', 'first name' and 'last name'. The 'status' could be blank or display 'complete' or 'missed' to indicate whether or not a resident had taken medications. The blank status suggested that the resident had not yet been attended. 'Complete' suggested that the resident had been medicated and the person had taken all the medications. 'Missed' suggested that the resident had been attended, but part or all of the medications had not been administered, because e.g. the resident refused to take the medications.

Clicking into a record, the resident's profile, including name, photo, allergies, special instructions and alert to the due date of non-daily medication would be shown. A 'confirm' button was provided to confirm that this profile matched the resident who was to be medicated.

In the next page, the resident's name, number of packed medications and whether the person had unpacked or short-course medication were given at the top of this page. Below were the medications to be administered to this person. Each medication was accompanied by 'drug name', 'frequency', 'dose', a checkbox to click to signal the completion of medication 
administration, and 'note' for any free text documentation. A 'done' button was provided to return to the resident listing screen. If any medication was not ticked, the eMAR would prompt a message asking for a reason. The eMAR could automatically populate the reason into the progress note of this resident.

During a medication round, data were stored on the portable device. To synchronize the data with the database, the device needed to be connected to the internet. When logging out, the eMAR would alert the user if the person did not sign the record.

The eMAR recorded the time of medication administration automatically. It could also call attention to changes and errors in a resident's medication profile. The short-course medication and nurse-initiated medication charts were not provided by the eMAR. They were recorded on paper-based charts.

\subsection{The paper-based records}

At Unit 2, nurses used paper-based medication administration records. Each resident had several pages of records which might include some or all of the following charts or sheets:

- a medication administration time chart

- a primary medication chart

- a packed medication signing sheet

- a non-packed medication signing sheet

- a short-course medication signing sheet

- a pro re nata medication signing sheet

- telephone orders 
- $\quad$ nurse-initiated medication signing sheet

Each signing sheet could be used to record information for a month. There was space to sign to signify the completion of each medication during a pre-defined time slot (e.g. morning). When signing for an administered medication, a nurse needed to write down the initials of their name. If a medication was not administered, the nurse must write a designated letter which provided a pre-defined reason (e.g. ' $N$ ' for no stock, ' $R$ ' for refuse and ' $H$ ' for hospital). During a medication round, the nurse also used an insulin administration book and a pain patch documentation book.

\subsection{Data collection methods}

Both quantitative and qualitative data were collected using four methods: time-motion based observation, informal conversation with medication staff, field notes and document review. Time-motion observation has been used by previous studies to evaluate the care processes in RACHs [11, 12]. It requires an observer to follow one participant at a time and sequentially record the time taken for the person to conduct an activity, using a pre-defined activity classification system.

The classification of activities in a medication round can be found in Table 2. They are documentation, verbal communication, medication administration (e.g. preparing and providing tablets), infection control (e.g. using an alcohol hand sanitizer), transit (e.g. pushing a medication trolley) and others (turning on a TV for a resident). Documentation activity has seven sub-activities: locating a resident's record (related or not related to medication), reading a resident's record (related or not related to medication), documenting on a resident's record (related or not related to medication) and collecting paper-based records/logging in or out the eMAR. Verbal communication has two sub-activities: verbal communication with residents and with other staff or visitors. 
Short informal conversation between the observer and the participant was conducted to collect information about what the participant liked or disliked about the electronic or paperbased records. The content of the conversation was included in the field notes. Other information that was not obtained from the time-motion recording and the informal conversation, but observed by the data collector, was also recorded in the field notes. Document review was also conducted. It included the organization's documentation requirements and seven-month medication incident reports in the RACH.

\subsection{Data collection}

A single data collector observed one participant on each day (6:30 a.m. to 3 p.m.) for 12 days, six in each unit. Time-motion data were recorded using commercial software InMotion Pro [13] installed on an iPad. Field notes were taken on paper. Medication rounds were usually conducted from 7 a.m. to 10 a.m. and from 12 p.m. to 1:30 p.m. On average, a morning medication round lasted three hours and a noon medication round lasted one hour and 20 minutes.

\subsection{Data analysis}

Work processes of nurses using the eMAR and the paper-based records in a medication administration process for a resident are shown in Figures 1 and 2. The workflow mapping method proposed by Kmetz [14] was used for its easy readability. It contains five visually distinct symbols: rectangle representing processes and activities, diamond representing two mutually exclusive decisions, circle representing start and stop, single direction arrow representing material or information flow and document representing paper input or output. The diagrams were validated by a registered nurse and two endorsed enrolled nurses. Field notes were entered into Word files for analysis. 
Data recorded in the iPad were exported to Microsoft Excel files for statistical analysis. The unit of analysis was individual activities. The difference between the two care units in the percentage of time nurses spent on each activity category or sub-activity was tested using a Z test. The Bonferroni adjustment was applied to take account of the multiple testing conducted in this analysis. Therefore, a statistically significant difference was defined by $\mathrm{p}<0.008$ (0.05/6). Non-medication-related documentation activities were not compared between the two care units because the number of these activity instances occurred was small.

\subsection{Ethics approval}

Ethics approval was given by the Ethics Committee of the University of Wollongong subject to the approval of the management of the RACH, which was subsequently provided.

\section{Results}

\subsection{Time nurses spent on activities in a medication round}

Table 2 shows the percentage of the time and minutes nurses spent on activities during a medication round at the two units. No significant difference between the two units was found in the percentage of time spent on each category of activities. Significant differences between the two units were found in two sub-activities of documentation: locating and reading medication-related records. The time nurses spent on locating and reading at Unit 1 was significantly less than it was at Unit 2.

Nurses at Unit 1, who used the eMAR, also did some paper-based documentation which accounted for $15 \%$ of the total documentation time, equivalent to 3 minutes in a three-hour medication round. Paper-based documentation accounted for $71 \%$ of nurses' time spent on documenting non-medication-related information, 69\% of nurses’ time spent on locating non- 
medication-related information, and approximately $50 \%$ of nurses' time spent on reading medication-related or non-medication-related records.

Table 2. The percentage of time and minutes nurses spent on each activity in a threehour medication round at the two units.

\begin{tabular}{|c|c|c|c|c|c|}
\hline \multirow[b]{2}{*}{ Category of activities } & \multicolumn{2}{|c|}{ Unit 1 (eMAR) } & \multicolumn{2}{|c|}{ Unit 2 (paper records) } & \multirow[b]{2}{*}{$P$ value } \\
\hline & $\begin{array}{l}\text { \% of time }(95 \% \\
\text { confidence } \\
\text { interval) }\end{array}$ & $\begin{array}{l}\text { Minutes in } \\
\text { a three- } \\
\text { hour } \\
\text { medication } \\
\text { round }\end{array}$ & $\begin{array}{l}\text { \% of time }(95 \% \\
\text { confidence } \\
\text { interval) }\end{array}$ & $\begin{array}{l}\text { Minutes in } \\
\text { a three- } \\
\text { hour } \\
\text { medication } \\
\text { round }\end{array}$ & \\
\hline Total documentation & $11.7(10.5-13.0)$ & 21.1 & $14.1(12.8-15.4)$ & 25.4 & 0.011 \\
\hline $\begin{array}{l}\text { Locating a resident's } \\
\text { record (medication-related) }\end{array}$ & $3.5(3.1-4.0)$ & 6.3 & $5.9(5.2-6.7)$ & 10.6 & $<0.0001$ \\
\hline $\begin{array}{l}\text { Locating a resident's } \\
\text { record (not medication- } \\
\text { related) }\end{array}$ & $0.3(0.1-0.5)$ & 0.6 & $0.1(0.0-0.2)$ & 0.2 & - \\
\hline $\begin{array}{l}\text { Reading a resident's record } \\
\text { (medication-related) }\end{array}$ & $0.4(0.2-0.6)$ & 0.7 & $0.9(0.6-1.1)$ & 1.6 & 0.004 \\
\hline $\begin{array}{l}\text { Reading a resident's record } \\
\text { (not medication-related) }\end{array}$ & $0.3(-0.1-0.6)$ & 0.5 & $0.03(0.0-0.1)$ & 0.1 & - \\
\hline $\begin{array}{l}\text { Documenting on a } \\
\text { resident's record } \\
\text { (medication-related) }\end{array}$ & $4.6(3.9-5.3)$ & 8.3 & $5.9(5.1-6.7)$ & 10.6 & 0.015 \\
\hline $\begin{array}{l}\text { Documenting on a } \\
\text { resident's record (not } \\
\text { medication-related) }\end{array}$ & $0.6(0.3-0.8)$ & 1.1 & $0.4(0.2-0.6)$ & 0.7 & - \\
\hline $\begin{array}{l}\text { Reading/writing on the } \\
\text { paper note or the handover } \\
\text { sheet }\end{array}$ & $1.1(0.8-1.4)$ & 2.0 & $0.8(0.5-1.1)$ & 1.4 & 0.178 \\
\hline $\begin{array}{l}\text { Collecting paper-based } \\
\text { records/logging in or out } \\
\text { the eMAR }\end{array}$ & $0.9(0.4-1.5)$ & 1.6 & $0.1(0.0-0.2)$ & 0.2 & - \\
\hline Total verbal communication & $21.5(17.9-25.1)$ & 38.7 & $23.8(19.0-28.6)$ & 42.8 & 0.452 \\
\hline $\begin{array}{l}\text { Verbal communication } \\
\text { with residents }\end{array}$ & $12.1(10.2-14.1)$ & 21.8 & $14.0(10.6-17.4)$ & 25.2 & 0.342 \\
\hline $\begin{array}{l}\text { Verbal communication } \\
\text { with other staff or visitors }\end{array}$ & $9.4(6.4-12.3)$ & 16.9 & $9.8(6.5-13.0)$ & 17.6 & 0.858 \\
\hline Medication administration & $49.1(45.3-52.9)$ & 88.4 & $47.6(43.5-51.8)$ & 85.7 & 0.607 \\
\hline Infection control & $3.5(2.7-4.3)$ & 6.3 & $3.3(2.6-3.9)$ & 5.9 & 0.637 \\
\hline Transit & $8.3(7.1-9.5)$ & 14.9 & $7.6(6.6-8.7)$ & 13.7 & 0.411 \\
\hline $\begin{array}{l}\text { Others (e.g. turning on a TV } \\
\text { for a resident) }\end{array}$ & $5.9(2.6-9.1)$ & 10.6 & $3.6(1.3-5.9)$ & 6.5 & 0.267 \\
\hline
\end{tabular}

- The activity was not compared due to small number of instances of this activities recorded.

A statistically significant difference between the two units was assumed when the p value was less than 0.008 . 


\subsection{Medication administration process for a resident using eMAR or paper-based records}

Figure 1 shows the work processes of medicating a resident using the eMAR. A nurse ticked the checkbox for each medication either before or after providing it (bold boxes in Figure 1). However, ticking the checkbox did not enter data into the eMAR. Only by clicking the 'done' button would the data be recorded in the system. The nurse always only hit the 'done' button after providing the medication.

Figure 2 illustrates the medication administration processes using paper-based records. Nurses documented on the resident's charts either before or after providing medication to the person (bold boxes in Figure 2). The organizational policy required that documentation be done after providing medication. Therefore the process of documenting before providing medication was not compliant with this policy. The time-motion data showed that this procedural problem was recorded $22(10.58 \%)$ times out of 208 medication administration processes in the morning and 19 (13.19\%) times out of 144 medication administration processes at noon. This problem was not observed with the use of the eMAR. 


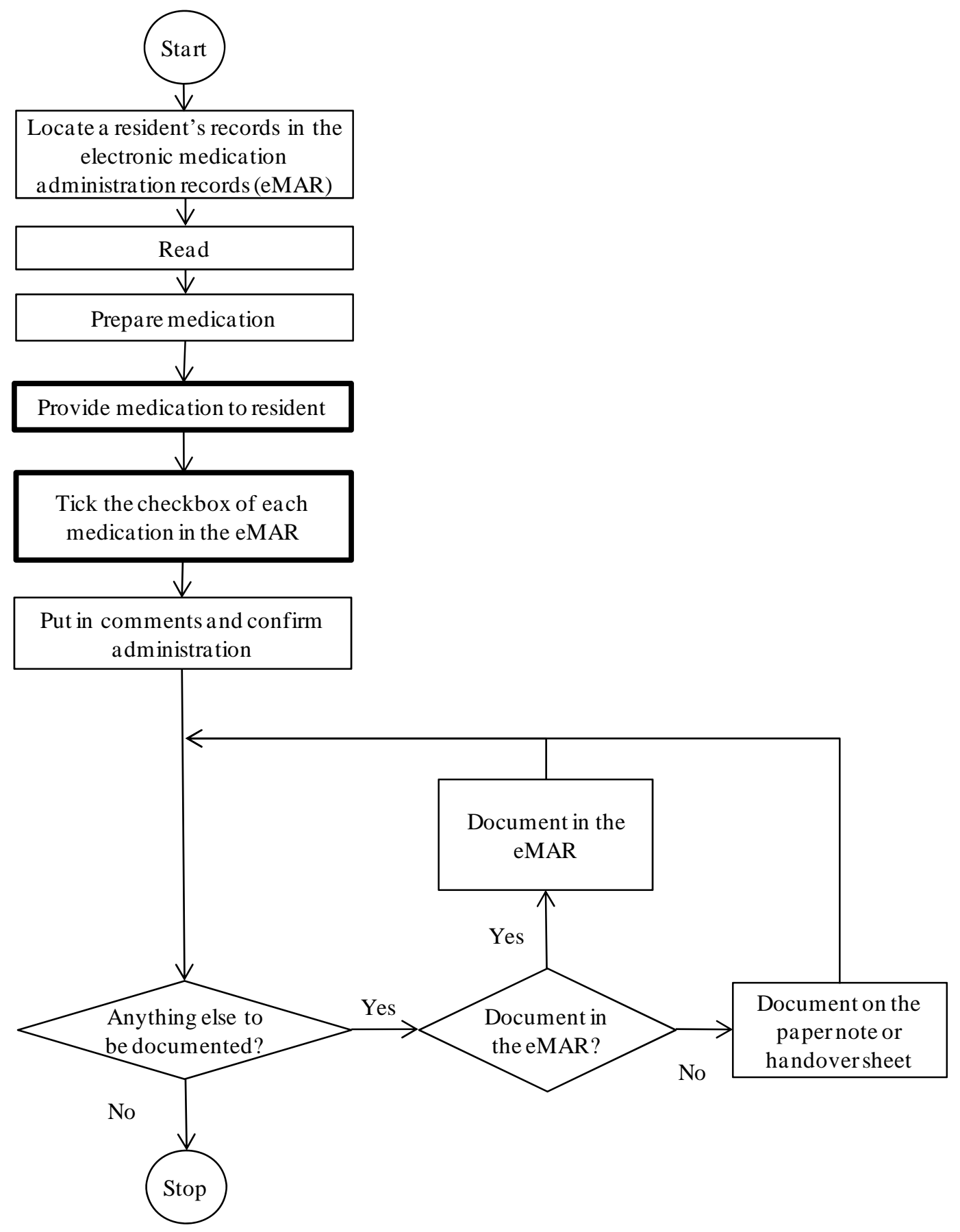

Figure 1. Using the electronic medication administration records (eMAR) during a medication administration process for a resident (the bold boxes can be switched). 


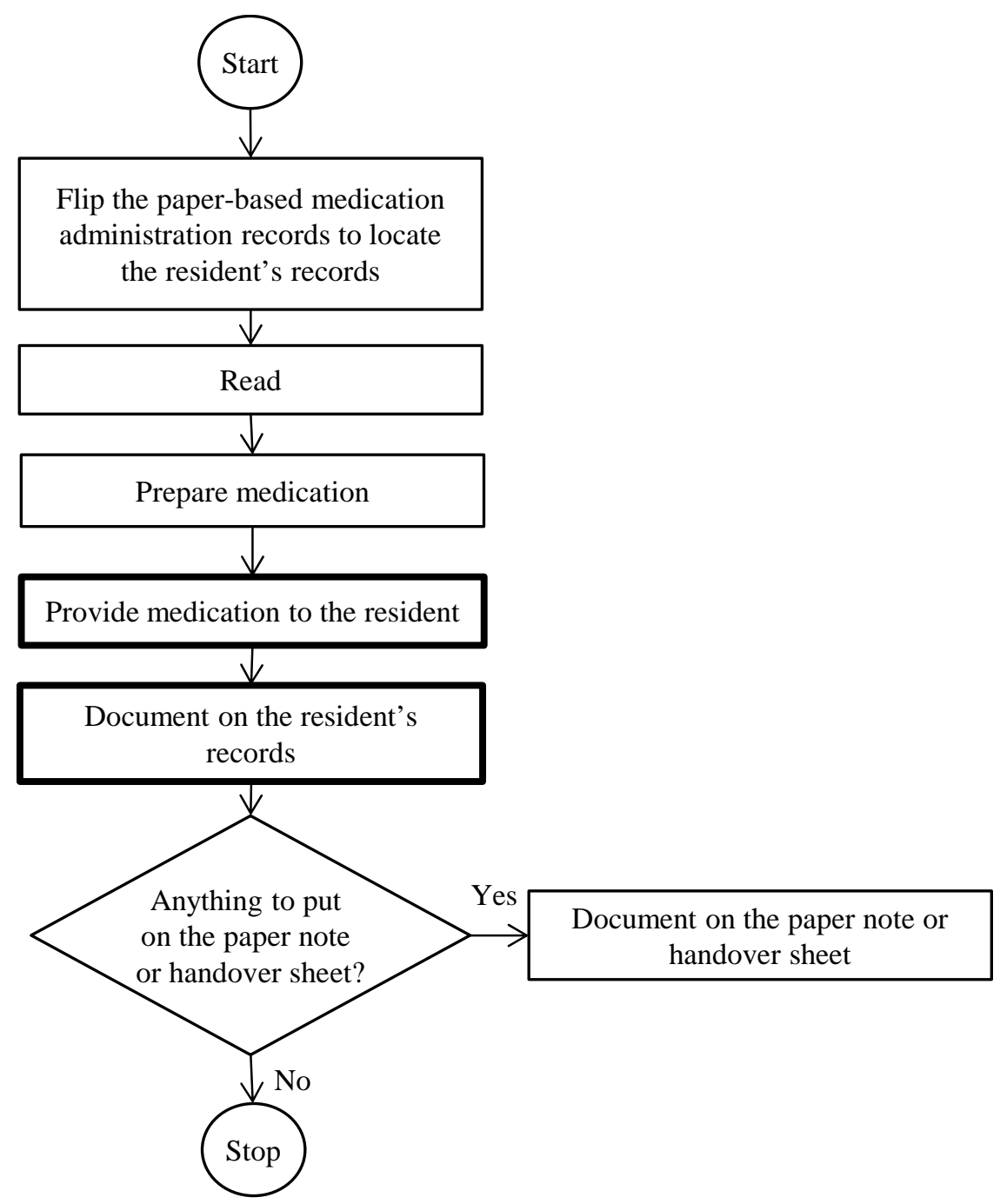

Figure 2. Using the paper-based medication administration records during a medication administration process for a resident (the bold boxes can be switched). 


\subsection{The impacts of the eMAR}

The impacts of the eMAR are summarized in Table 3.

Table 3. The impacts of the eMAR.

\begin{tabular}{|l|l|}
\hline \multicolumn{1}{|c|}{ Benefits } & \multicolumn{1}{c|}{ Unintended adverse consequences } \\
\hline - $\begin{array}{l}\text { Improving nurses' compliance with organization's } \\
\text { documentation requirements }\end{array}$ & $\begin{array}{l}\text { Inadequate information about residents in the } \\
\text { eMAR }\end{array}$ \\
- Freedom from the error of signing twice & $\begin{array}{l}\text { Reducing the possibility of nurses' forgetting to } \\
\text { medicate a resident } \\
\text { profile in the eMAR }\end{array}$ \\
$\begin{array}{l}\text { Facilitating nurses to record the time of } \\
\text { medication administration to a resident }\end{array}$ & $\begin{array}{l}\text { Nurses' forgetting to medicate a resident due to } \\
\text { power outage of the portable device }\end{array}$ \\
Increasing documentation space &
\end{tabular}

\subsubsection{Benefits with the eMAR}

Improving nurses' compliance with documentation requirements. The organization's documentation requirements clearly defined that the documentation should be done before moving on to the next person. When using the paper-based records, the nurses sometimes gave several residents medications before signing their charts. Nurses might do this in an attempt to save time, but it did not comply with the organizational policy. This problematic documentation practice was not observed when using the eMAR.

Freedom from the error of signing twice. When there was one-month signing space available on one piece of paper, this provided plenty of chances for signing a medication twice under two dates. One error recorded in the medication incident reports was that a nurse signed the medication chart twice when using the paper-based records because she forgot that she had done it after interruption by other care staff in the medication administration process. The eMAR had alleviated this error by letting a nurse select the medication round time immediately after logging into the system and recording the date and time of this round. 
Reducing the possibility of nurses' forgetting to medicate a resident or to sign on medication charts. The eMAR provided good support for a nurse to remember which resident had or had not been given medication. If a resident had not been medicated or chart not signed, the 'status' of this person in the eMAR would be blank. It was easy for the nurse to notice it, otherwise the eMAR would prompt the nurse with a message about it when logging out the system.

This was much more convenient than using the paper-based records. When using paper-based records, nurses invented a technique to help them remember who had or had not taken medication. They pulled the first page of a resident's paper records half out to indicate that the person had not been medicated. After the person was given medication, they pushed the page back. Nurses also flipped through the record book at the end of a medication round to check if all the medication charts were signed. However, sometimes nurses did not do these procedures.

Facilitating nurses to record the time of medication administration for a resident. Nurses mentioned that, if a resident had the same medication at both morning and noon, they would try to leave the time gap between the two administrations as long as possible. Therefore, they needed to know when a medication was given to the resident in the morning. The eMAR recorded the time of medication administration and it was easy to access this information next time. It was not easy to do this with the paper-based record.

Increasing documentation space. The eMAR provided free-text space for a nurse to document extra information. For example, the nurse could document the reason for missed medication by selecting the pre-defined reasons from a drop-down list, or type in the reason in the free-text box. When using the paper-based records, such information could only be 
noted using the pre-defined letters, because of a lack of space to write more. Any further information was documented on the paper note or the handover sheet.

\subsubsection{Unintended adverse consequences with the eMAR}

Inadequate information about residents. One nurse expressed her need to review what medication had been given to a resident in previous shifts. This could be done easily in paperbased records. Paper-based records provided a good overview of the history of medication administration of a resident, with all the medication administration records over 24 hours and one month displayed on one page. However, data in eMAR on a portable device was cleared at 12 a.m. every day. Data recorded from shifts in previous days were not accessible on the device at the point-of-care, but on desktop computers, as they were synchronized in the database.

The common weakness of both the eMAR and the paper-based records was not providing nurses with the convenience of sharing information about how a resident took a medication. Sharing information about what methods should be used to provide medication to a resident was needed in order to maintain quality of care and promote person-centered care. Although this information could be given by the eMAR in the 'special instructions' box, this was not done. We observed that, to provide the same medication to the same resident, different nurses used different methods. For example, a nurse fed a resident with spoon but another one let the person take the medication by himself.

Late addition of a new resident's medication profile in the eMAR. When a new resident was admitted to the RACH, it took approximately five days for the pharmacy to upload the person's medication profile into the eMAR. During this period, nurses had to document for this person on paper-based records. After a long and stressful medication round, nurses may forget to medicate the new person or forget to sign on the charts, since all the other residents' 
records were in the eMAR except this person. The only way to prevent this oversight was for the nurse to check the paper-based records at the end of the medication round. In one case, while checking the paper-based records, the nurse found that she forgot to give medication to a resident, so she went back to give medication to that person.

Nurses' forgetting to medicate a resident due to power outage of the portable device. The battery life of the portable device was usually long enough for one medication round, but power outage was observed once in the middle of a round. The portable device prompted a low battery message at the bottom right corner on the screen, however the nurse failed to notice and the device was powered off a few minutes later.

As the nurse did not properly log out of the system and connect the device to the internet, the data stored in the device was not synchronized with the server and with another portable device. Although the nurse used the other device to continue the medication round, she could only rely on her memory about who had or had not been medicated. This resulted in the nurse forgetting to medicate a resident, but fortunately the person came to the nurse for his medication.

\section{Discussion}

In this study, direct observations were conducted of how nurses used eMAR in two high-care units in an Australian RACH. It measured and compared how nurses used the eMAR in the two units. It also highlighted the potential qualitative value of introducing the eMAR.

\subsection{Impact on nurses' time expenditure}

One of the original expectations for the introduction of eMAR was to reduce nurses' time spent on documentation to give them more time on direct resident care. However, our study found that there was no significant reduction in documentation time, as the nurses did not 
spend much time on documentation at the first place (less than 30 minutes in a medication round). This may suggest that the major benefit of using eMAR was not improving documentation efficiency. As the study was conducted in one RACH, its generalizability might be limited.

The use of the eMAR did not impact on the time nurses spent on other categories of activities including medication administration and verbal communication. This finding is similar to a longitudinal work sampling study which examined the impact of an electronic health record system on nursing staff time in a high-care unit in an Australian RACH [15]. It also found that the introduction of the system might not interfere with nursing staff time on direct care duties.

This study found significant reduction in the time nurses spent on locating and reading a resident's medication-related record. This time reduction (4 minutes) might be attributed to nurses being able to easily identify a record from the list of all residents on just one screen, rather than flipping through the thick paper-based records.

The time reduction in reading, although statistically significant, may not be important, because the actual reading time is only about 1 minute, for both the eMAR and the paperbased records. This may be because these nurses regularly worked in the two units and were familiar with residents’ medications.

\subsection{Impact on the medication administration process for a resident}

A previous study found nurses overrode important safety workflow blocks designed intentionally in the eMAR because they were time consuming [10]. Our study found that the use of the eMAR can positively change nurses' documentation behavior, improving their compliance with the organizational protocol. This may be because it was not as easy for 
nurses to quickly switch between different residents' entries in the eMAR as with the paperbased records.

Correct documentation behavior can facilitate nurses in recording accurate data, which are important for managing quality of care and resident safety. As nurses' documentation behavior can be influenced by time constraints, the designers of the eMAR must consider the efficiency of using the eMAR in reality when designing safety features in the eMAR. If these safety features can be seamlessly integrated into nurses' work processes, they can positively shape the work processes and contribute to resident safety.

\subsection{Benefits and unintended adverse consequences of introducing the eMAR}

Medication administration requires high concentration, so nurses' cognitive load in the medication round is high. If interrupted, nurses may forget to medicate a resident or sign on medication charts. The eMAR can reduce the possibility of such events by providing functions to remind and alert nurses. However, this benefit can be hindered by related work processes that were not integrated effectively with the eMAR and device deficiencies have fostered an error-prone environment. This suggests that processes and devices that will interface with the eMAR need to be carefully designed to facilitate the effective use of the eMAR.

The eMAR allowed nurses to focus on medications that are due in a specific time frame $[1,8]$. This feature can prevent dating and timing errors. However, it did not meet nurses' need to review information from previous shifts. This suggests that nurses have multiple requirements in the amount of information given by the eMAR when administering medication. When designing the eMAR, the designers must understand when nurses will need what information and give nurses the flexibility of accessing the needed information in the eMAR. 
The increased documentation space, especially the free-text space, provided by the eMAR compared to the paper-based records offered an opportunity for important medication-related information to be documented and stored immediately. However, the speed of entering freetext data might be a concern to nurses who aim for high efficiency. The managers of RACHs may consider providing physical keyboards to facilitate quick free-text data entry, but also need to consider the physical space available on the medication trolley which has been filled with the portable device, some paper-based records, spoons and cups, water and juice, etc.

Despite the increased documentation space in the eMAR, some useful information (e.g. use a spoon to provide medication) about residents has not been shared in the eMAR, which should have facilitated person-centered care. Nursing managers need to develop strategies to collect and enter these data about residents' personal preference in taking medication. This information will be useful for nurses in sharing knowledge and facilitating caring for new residents, especially in this high staff turnover care environment.

A limitation of this study was that the number of nurses observed was small. Another limitation is that the two groups of nurses compared in this study were not exactly the same in terms of type and number of nurses.

\section{Conclusion}

The eMAR did not necessarily change the time nurses spent on various activities such as medication administration, verbal communication and documentation. The medication administration processes followed by nurses were similar between the use of the eMAR and the paper-based records, but the use of the eMAR has the potential to improve nurses' documentation compliance and workflow. 
In addition, the eMAR can help to prevent the error of signing a medication twice, reduce the possibility of nurses' forgetting to medicate a resident, facilitate the recording of medication administration time and increase documentation space. Unintended adverse consequences of the eMAR included inadequate information about residents in the eMAR, late addition of a new resident's medication profile and nurses' forgetting to medicate a resident when there was power outage of the portable device.

To maximize the benefits of introducing eMAR, managers need to be able to predict and plan for the unintended adverse consequences before purchasing and implementing the system. They need to consider, for example, whether the system meets daily documentation needs, how the staff on the floor will actually use the system and whether specific work processes should be adjusted to support efficient work rather than hindering efficiency or providing chances for potential errors. The eMAR designers must fully understand what information is needed by nurses at what time and in what format in order to effectively support medication administration. Future research may investigate whether and how the unintended adverse consequences can be prevented.

\section{Acknowledgements}

The authors gratefully acknowledge all the participant nurses and the support from the management of the residential aged care home.

\section{Conflicts of interest: none.}

\section{Authors' contributions}

SQ and PY conceptualized the study. SQ collected and analyzed data. SQ drafted the manuscript. PY and DH critically reviewed the manuscript. 


\section{References}

[1] J. Scott-Cawiezell, R.W. Madsen, G.A. Pepper, A. Vogelsmeier, G. Petroski, D. Zellmer, Medication safety teams' guided implementation of electronic medication administration records in five nursing homes, Jt. Comm. J. Qual. Patient Saf. 35 (1) (2009) 29-35.

[2] L. Furniss, Use of medicines in nursing homes for older people, Advances in Psychiatric Treatment 8 (3) (2002) 198-204.

[3] M.M. Elseviers, R.R. Vander Stichele, L. Van Bortel, Drug utilization in Belgian nursing homes: impact of residents' and institutional characteristics, Pharmacoepidemiology and drug safety 19 (10) (2010) 1041-1048.

[4] J.A. Doshi, T. Shaffer, B.A. Briesacher, National Estimates of Medication Use in Nursing Homes: Findings from the 1997 Medicare Current Beneficiary Survey and the 1996 Medical Expenditure Survey, J. Am. Geriatr. Soc. 53 (3) (2005) 438-443.

[5] A. Szczepura, D. Wild, S. Nelson, Medication administration errors for older people in long-term residential care, BMC Geriatr. 11 (1) (2011) 82.

[6] A. Tariq, A. Georgiou, J. Westbrook, Medication errors in residential aged care facilities: A distributed cognition analysis of the information exchange process, Int. J. Med. Inf. 82 (5) (2012) 299-312.

[7] C. Edgar, P. Harvey, Common Medication Errors in Long-Term Care Settings, Medication Management in Older Adults (2010) 53-67.

[8] K. Oliver, M. Raban, M. Baysari, J. Westbrook, Evidence briefings on interventions to improve medication safety: Electronic medication administration records, Australian commission on safety and quality in health care 1 (5) (2013). 
[9] M. Baysari, E. Lehnbom, J. Westbrook, Evidence briefings on interventions to improve medication safety: Bar code medication administration systems, Australian commission on safety and quality in health care 1 (1) (2013).

[10] A.A. Vogelsmeier, J.R. Halbesleben, J.R. Scott-Cawiezell, Technology implementation and workarounds in the nursing home, J. Am. Med. Inform. Assoc. 15 (1) (2008) 114-119.

[11] S. Qian, P. Yu, D.M. Hailey, Z. Zhang, P.J. Davy, M.I. Nelson, Time spent on daytime direct care activities by personal carers in two Australian residential aged care facilities: A time-motion study, Aust. Health Rev. 38 (2) (2014) 230-237.

[12] S. Qian, P. Yu, Z. Zhang, D. Hailey, P. Davy, M. Nelson, The work pattern of personal care workers in two Australian nursing homes: A time-motion study, BMC Health Serv. Res. 12 (1) (2012) 305.

[13] Code Studio, InMotion Pro - Time Study, https://itunes.apple.com/us/app/inmotionpro/id896925457?mt=8 (accessed 9 Dec 2014).

[14] John Kmetz, Mapping Workflows and Managing Knowledge: Simply, Sensibly, Flexibly, and without Software, Transition Assistance Associates, Newark, Delaware, 2010.

[15] E.N. Munyisia, P. Yu, D. Hailey, The effect of an electronic health record system on nursing staff time in a nursing home: A longitudinal cohort study, Australas. Med. J. 7 (7) (2014) 285-293. 